\title{
SIMULASI UNBK UNTUK SISWA/SISWI TINGKAT SMA
}

\author{
Nazario Martins Caeira ${ }^{1}$, Dewi Anggraini' ${ }^{2}$, Max ABR Soleman Lenggu ${ }^{3}$ \\ Program Studi Sistem Informasi ${ }^{123}$ STIKOM Uyelindo Kupang \\ E-mail:riorpl75@gmail.com thewi_1205@yahoo.com
}

\begin{abstract}
Computer Based National Examination (UNBK) is a national examination implementation system using computers as the test media. In its implementation, UNBK is different from the paper-based national examination system or Paper Based Test (PBT) which has been running so far. Over time the process of implementing the UNBK still experiences many obstacles and obstacles experienced by students, especially those who live in remote villages, namely the lack of understanding and lack of use of information technology. They are still confused to use information technology equipment such as computers to deal with UNBK later. Based on a review of the problems that occur the author will create a website as a UNBK simulation media, with the aim to simulate the implementation of the $U N B K$, so that students understand and are familiar with the process of implementing the UNBK. Waterfall is a classic model that is systematic, sequential in building software
\end{abstract}

Keywords: UNBK, Simulation, Website, Waterfal

\section{PENDAHULUAN}

\subsection{Latar Belakang}

Seiring dengan perkembangan teknologi, maka banyak sekali proses bisnis yang beralih ke alat digital dan komputerisasi, banyak pekerjaan yang semula dikerjakan oleh manusia sekarang mulai diganti dengan mesin dan komputer. Hal ini terjadi di berbagai sektor kehidupan. Mulai dari sektor ekonomi, perbankan, pertanian, industri dan sektor pendidikan. Menurut [1], setiap anak berhak memperoleh pendidikan yang baik, pemerintah dan masyarakat memiliki tugas dan tanggungjawab untuk menjalankan pendidikan baik.

Salah satu perubahan yang sekarang terjadi di sektor pendidikan adalah dengan adanya UNBK yang merupakan singkatan dari Ujian Nasional Berbasis Komputer yang dapat diselenggarakan di sekolah-sekolah setingkat SMP dan SMA dan sederajat dengan menggunakan perangkat lunak tertentu sebagai pengganti ujian nasional secara tertulis. Pesertanya adalah siswa dengan beberapa ketentuan sesuai peraturan yang berlaku yang dikeluarkan oleh pihak-pihak yang berwenang dari tingkat provinsi hingga tingkat pusat [6]

Ujian Nasional Berbasis Komputer (UNBK) disebut juga Computer Based Test (CBT) adalah sistem pelaksanaan ujian nasional dengan menggunakan komputer sebagai media ujiannya. Dalam pelaksanaannya, UNBK berbeda dengan sistem ujian nasional berbasis kertas atau Paper
Based Test (PBT) yang selama ini sudah berjalan.

Dalam pelaksanaan UNBK ini masih mengalami banyak hambatan dan kendala yang dialami siswa-siswi khususnya yang tinggal di pelosok-pelosok desa, yakni kurangnya pemahaman dan minimnya penggunaan teknologi informasi. Mereka masih bingung untuk menggunakan peralatan-peralatan teknologi informasi seperti komputer untuk menghadapi UNBK nantinya. Dari data yang peneliti dapatkan dari website https://ubk.kemdikbud.go.id bahwa di NTT sendiri masih banyak sekolah-sekolah yang belum melaksanakan UNBK, yakni dari data presentasi jumlah sekolah yang mengikuti UNBK paling tertinggi ada di Kota Kupang mencapai $70 \%$, sedangkan yang terendah ada di Kabupaten Sumba hanya mencapai 15\% sekolah yang megikuti UNBK. Dari hasil presentasi yang ada dapat disimpulkan bahwa sekitar 50\% masih banyak siswa-siswi yang masih belum paham tentang UNBK karna keterbelakangan peralatan teknologi informasi. Dengan melihat permasalahan yang terjadi penulis akan membuat sebuah website sebagai media simulasi UNBK, sehingga memudahkan siswa/siswi untuk berlatih menghadapi UNBK dimanapun mereka berada. Berdasarkan hal ini penulis tertarik untuk membuat proposal penelitian yang berjudul "Simulasi UNBK untuk Siswa/Siswi Tingkat SMA" 


\subsection{Permasalahan}

Adapun rumusan masalah yang diambil dalam penelitian ini yakni Bagaimana merancang dan membangun sebuah website yang ditujukan untuk simulasi UNBK?

\subsection{Tujuan Penelitian}

Tujuan dari penelitian ini adalah untuk membangun sebuah website untuk mengsimulasikan pelaksanaan UNBK, sehingga siswa/siswi mengerti dan terbiasa dalam proses pelaksanaan UNBK.

\section{LANDASAN TEORI}

\subsection{Simulasi}

Simulasi merupakan teknik penyusunan model dari suatu keadaan nyata (sistem) dan kemudian melakukan percobaan pada model tersebut. Simulasi merupakan alat yang fleskdibel dari model atau metode kuantitatif. Pada umumnya simulasi cocok bila diterapkan untuk menganalisa interaksi masalah yang rumit dari sistem sedangkan penggunaan teknik analisa yang ada terbatas. Simulasi juga berguna untuk mengetahui pengaruh atau akibat suatu keputusan dalam jangka waktu tertentu [7].

\subsection{Ujian Nasional Berbasis Komputer (UNBK)}

UNBK adalah sebuah sistem ujian nasional dimana dalam pelaksanaannya menggunakan media komputer. Sistem ini dalam bahasa inggris disebut juga dengan CBT atau Computer Based Test. Ujian Nasional Berbasis Komputer ini berbeda dengan Paper Based Test atau sistem ujian nasional berbasis kertas [6].

Pelaksanaan UNBK dalam sistem pendidikan nasional mulai dirintis penerapannya pada tahun 2013 di sekolah Indonesia di Singapura dan Malaysia. Sekolah tersebut dipilih karena kesiapan sekolah dan ketersediaan fasilitas komputer untuk digunakan peserta didik dalam ujian. Sekolah tersebut merupakan sekolah rintisan dalam penerapan UNBK dan sekaligus merupakan jawaban atas permintaan pimpinan kementerian yang menginginkan penyempurnaan dalam pelaksanaan ujian nasional yang selama ini dilakukan dalam bentuk tertulis [4].

\subsection{Website}

Website atau situs dapat diartikan sebagai kumpulan halaman-halaman yang digunakan untuk menampilkan informasi teks, gambar diam atau gerak, animasi, suara, dan atau gabungan dari semuanya, baik bersifat statis maupun dinamis yang membentuk satu rangkaian bangunan yang saling terkait, yang masingmasing dihubungkan dengan jaringan-jaringan halaman. Hubungan antara satu halaman web dan halaman web yang lainnya disebut hyperlink, sedangkan teks yang dijadikan media penghubung disebut hypertext [2].

\section{METODOLOGI}

Metodologi adalah proses mulai dari mendapatkan data sampai dengan perancangan program yang direncanakan. Adapun beberapa metodologi yang penulis gunakan diantaranya :

a. Metodologi Penelitian

Metode penelitian merupakan cara yang digunakan untuk menyelesaikan suatu penelitian tentang suatu masalah [3]

Untuk dapat menyelesaikan penelitian tentang perangkat tweaking ini, maka penulis menggunakan berbagai macam langkah dan cara di antaranya adalah sebagai berikut :

i. Jenis Penelitian

Adapun jenis penelitian yang digunakan penulis dalam penulisan skripsi ini adalah jenis penelitian experimen.

ii. Jenis dan Sumber Data

Jenis data yang digunakan penulis dalam penelitian ini adalah jenis data kualitatif, dimana data yang didapatkan penulis berupa keterangan yang menjelaskan permasalahan yang berhubungan dengan aspek yang diteliti dalam hal ini menyangkut Sistem Operasi Windows dan jenis data kuantitatif yang dirangkum penulis berupa angkaangka yang berhubungan jumlah kapasitas hardisk, memory maupun processor yang mendukung Sistem Operasi Windows.

Sedangkan sumber data yang dibutuhkan dalam penelitian ini adalah Data Primer dan Data Sekunder. Data primer yaitu data yang dikumpulkan secara langsung oleh peneliti yang berasal dari konfigurasi standar Windows itu sendiri, sedangkan data sekunder yaitu data yang dikumpulkan berkaitan dengan data pendukung dari data primer [3].

iii. Teknik Pengumpulan Data

Proses pengumpulan data yang dilakukan penulis guna memperoleh keakuratan datadata penelitian ini menggunakan dua jenis metode diantaranya adalah :

1. Studi Pustaka

Dalam metode ini peneliti menggunakan konsep teoritis yang bersumber dari literatur-literatur terkait 
yang berhubungan dengan obyek dan ruang lingkup penelitian.

2. Metode Experimen

Penelitian dengan metode experimen adalah suatu penelitian yang berusaha mencari pengaruh variable tertentu terhadap variable yang lain dalam kondisi yang terkontrol secara tepat.

b. Prosedur Penelitian

Prosedur analisis data yang digunakan oleh penulis ialah menggunakan metode waterfall. Waerfal adalah model klasik yang bersifat sistematis, berurutan dalam membangun software [5]

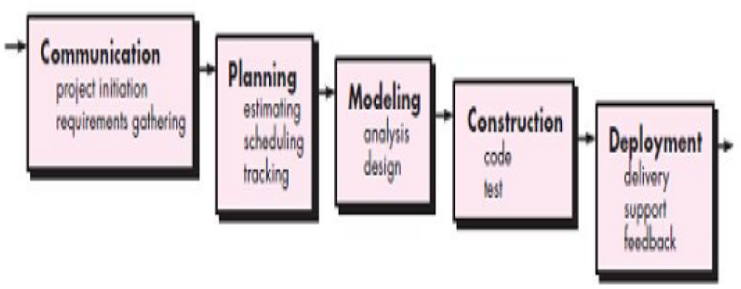

Gambar 1. Model Waterfall [5]

\section{Communication}

Langkah ini merupakan analisis terhadap kebutuhan software, dan tahap untuk mengadakan pengumpulan data dengan melakukan pertemuan dengan customer, maupun mengumpulkan data-data tambahan baik yang ada di jurnal, artikel, maupun dari internet.

\section{Planning}

Proses planning merupakan lanjutan dari proses communication (analysis requirement). Tahapan ini akan menghasilkan dokumen user requirement atau bisa dikatakan sebagai data yang berhubungan dengan keinginan user dalam pembuatan software, termasuk rencana yang akan dilakukan.

\section{Modeling}

Proses modeling ini akan menerjemahkan syarat kebutuhan ke sebuah perancangan software yang dapat diperkirakan sebelum dibuat coding. Proses ini berfokus pada rancangan struktur data, arsitektur software, representasi interface, dan detail (algoritma) prosedural. Tahapan ini akan menghasilkan dokumen yang disebut software requirement.

\section{Contruction}

Construction merupakan proses membuat kode. Coding atau pengkodean merupakan penerjemah desain dalam bahasa yang bisa dikenali oleh komputer. Programmer akan menerjemahkan transaksi yang diminta oleh user. Tahapan inilah yang merupakan tahapan secara nyata dalam mengerjakan suatu software, artinya penggunaan komputer akan dimaksimalkan dalam tahapan ini. Setelah pengkodean selesai maka akan dilakukan testing terhadap sistem yang telah dibuat tadi. Tujuan testing adalah menemukan kesalahan - kesalahan terhadap sistem tersebut untuk kemudian bisa diperbaiki.

\section{Deployment}

Tahapan ini bisa dikatakan final dalam pembuatan sebuah software atau sistem. Setelah melakukan analisis, desain dan pengkodean maka sistem yang sudah jadi akan digunakan oleh user. Kemudian software yang telah dibuat harus dilakukan pemeliharaan secara berkala.

c. Perancangan Sistem

1. Use Case Diagram
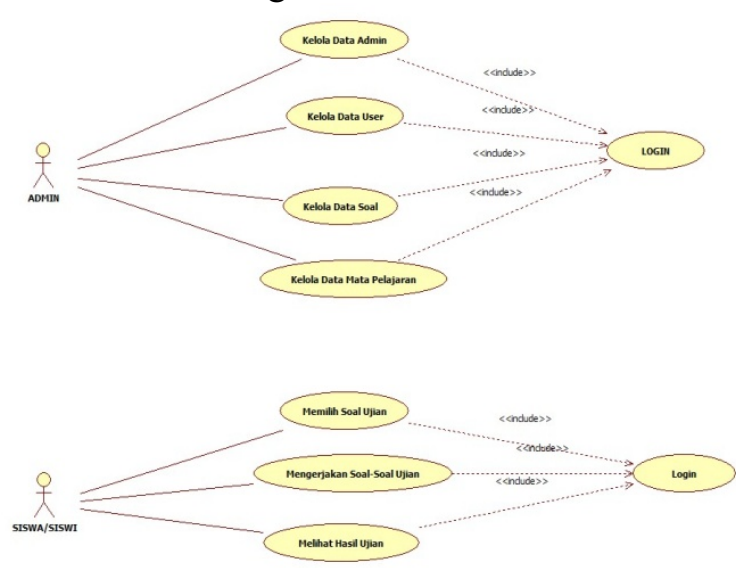

Gambar 2. Use Case Diagram

2. Class Diagram

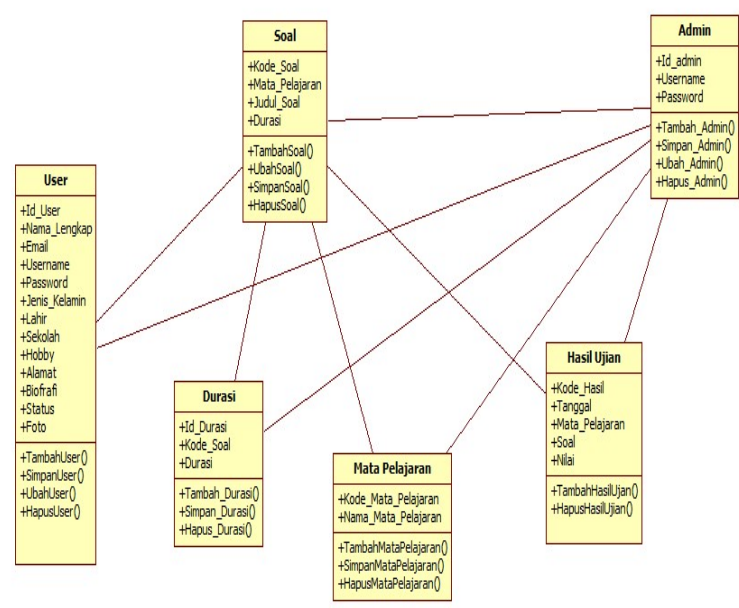

Gambar 3. Class Diagram 


\section{HASIL DAN PEMBAHASAN}

4.1 Implementasi Sistem Implementasi merupakan suatu penerapan cara kerja yang dilakukan berdasarkan hasil perancangan dan analisa yang telah dibuat sebelumnya ke bahasa pemrograman php.

\section{a. Halaman Login}

1. Halaman Login Admin

Halaman ini berfungsi untuk memberikan akses kepada Admin utama untuk mengolah data-data soal ujian untuk siswa-siswi serta mengolah dan mengontrol data-data dari siswa-siswi yang mengambil bagian dari simulasi UNBK.

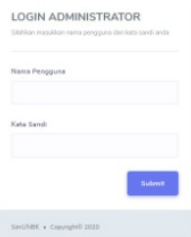

Gambar 4. Halaman Login Admin

2. Halaman Login User

Halaman ini berfungsi untuk memberikan hak akses kepada user atau pengguna yakni siswa-siswi agar bisa mulai memilih dan mengerjakan soal-soal yang telah disediakan dalam sistem.
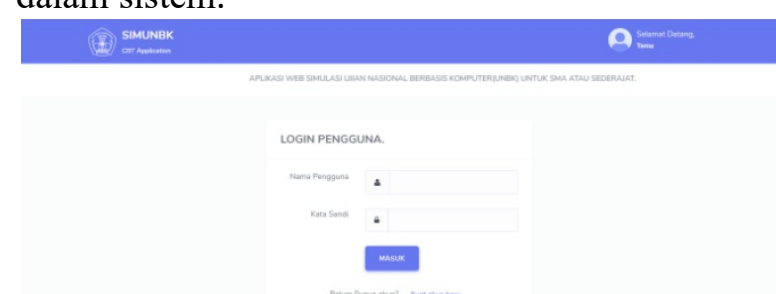

Gambar 5. Halaman Login User

3. Halaman Beranda Awal

Halaman beranda awal merupakan tampilan awal website simulasi ini dan terdapat menu untuk login dan daftar pengguna
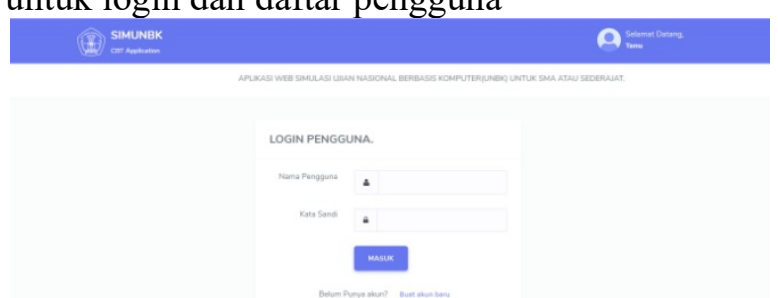

Gambar 6. Halaman Beranda Awal

b. Halaman User
Halaman User bisa di akses ketika user sudah login. Dalam halaman user terdapat 3 menu yaitu Beranda, Pilih Tes, Ujian Saya. Berikut penjelasannya:

1. Beranda User

Beranda User terdapat langkah-langkah pengerjan soal-soal atau petunjuk pengerjan.

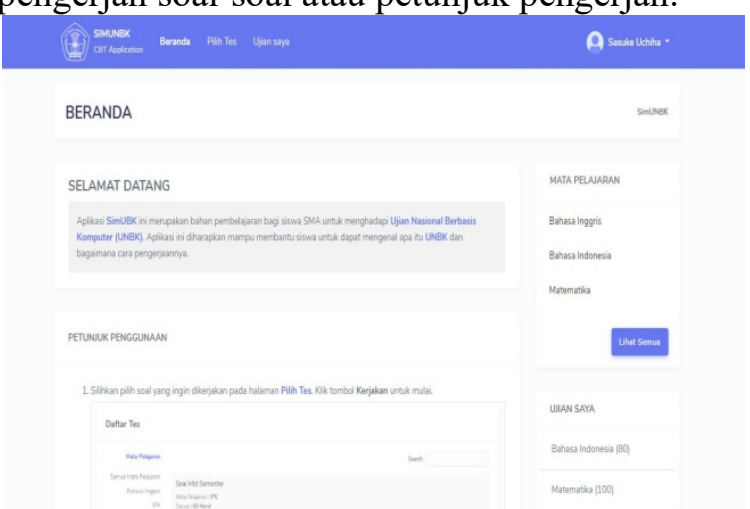

Gambar 7. Halaman Beranda User

2. Pilih Tes

Menu pilih tes terdapat 4 mata pelajaran yang bisa user pilih untuk di kerjakan lebih dahulu yakni Matematika, Bahasa Indonesia, Bahasa Inggris dan IPA.

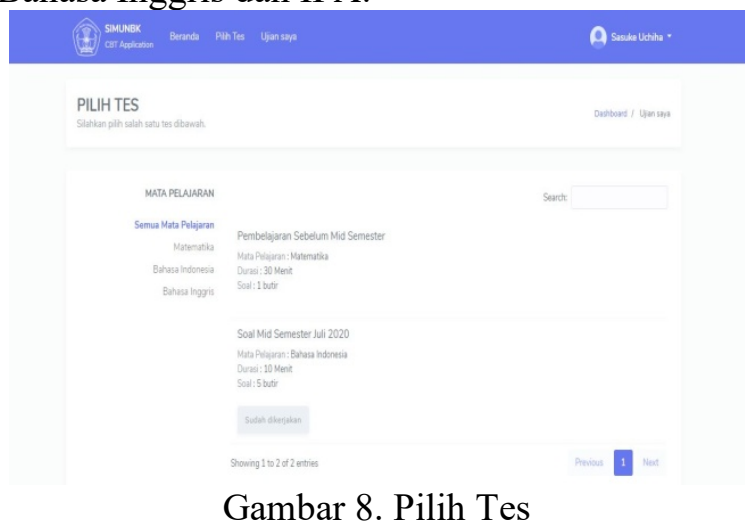

3. Ujian Saya

Ujian saya, dalam menu ujian saya itu terdapat rekapan atau riwayat pengerjaan user itu sendri.

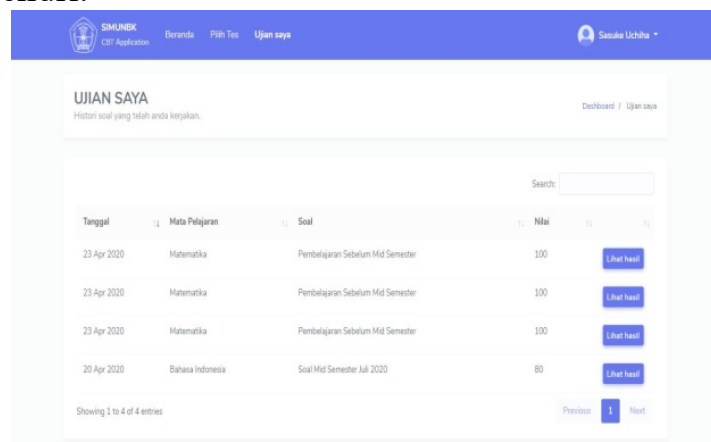

Gambar 9. Hasil Ujian User

c. Halaman Admin 
Halaman Admin merupakan halaman khusus untuk admin, dalam halaman tersebut admin mempunyai tugas untuk mengolah datadata simulasi seperti mempersiapkan soal-soal dan lainnya. Dalam halaman admin terdapat 54menu yaitu Mata Pelajaran, Soal, Pertanyaan dan Pengguna. Berikut penjelasannya:

1. Menu Mata Pelajaran

Menu Mata Pelajaran berisi tentang data-data mata pelajaran yang dicantumkan dalam simulasi.

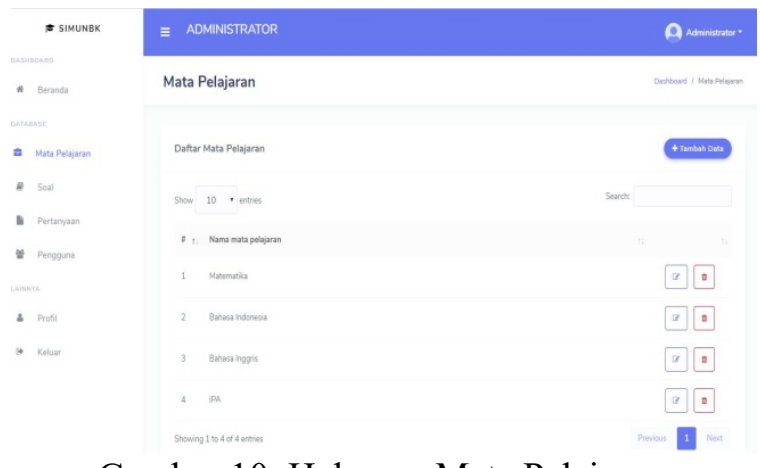

Gambar 10. Halaman Mata Pelajaran

2. Halaman Soal

Halaman Soal berisi tentang jenis soal yang akan di kerjakan user.
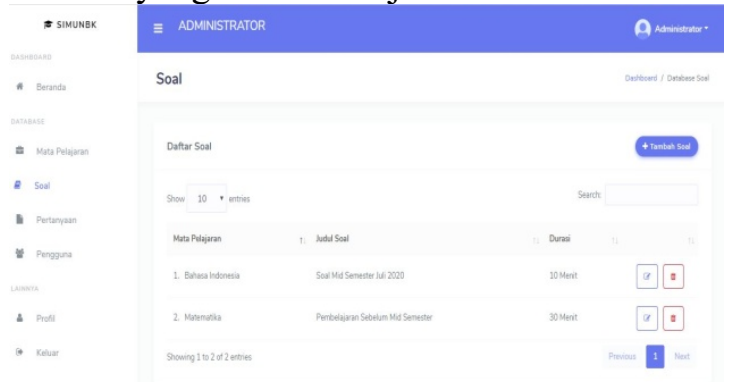

Gambar 11. Halaman Soal

3. Halaman Pertanyaan

Halaman Pertanyaan Berisi tentang pertanyaan-pertanyaan yang nantinya di gabung dalam satu soal.

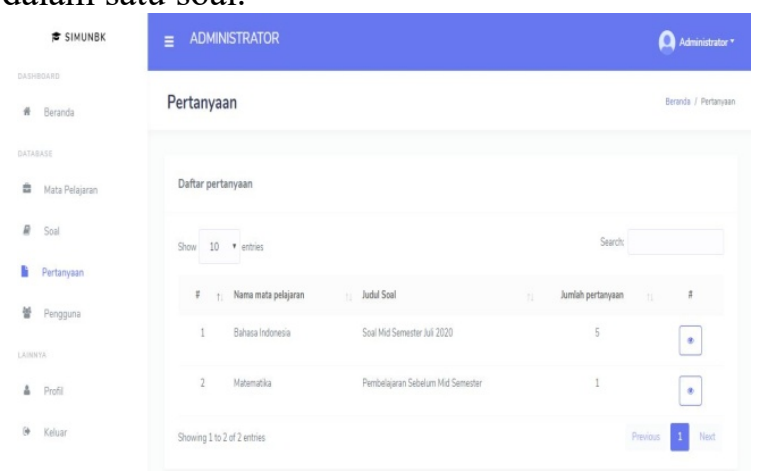

Gambar 12. Halaman Pertanyaan
4. Halaman Pengguna

Halaman pengguna merupakan profil-profil dari pengguna yang di control langsung oleh admin.

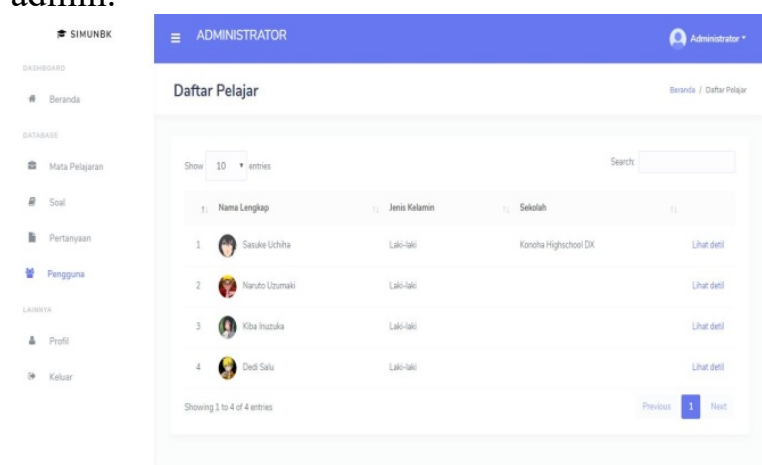

Gambar 13. Halaman Pengguna

\section{KESIMPULAN}

\subsection{Kesimpulan}

Berdasarkan hasil dan pembahasan maka dapat disimpulkan bahwa simulasi UNBK yang dibuat ini dapat membantu siswa/siswi untuk dapat belajar dan mampu membuat siswa/siswi terbiasa untuk menghadpi UNBK sebelum UNBK itu datang. Simulasi UNBK yang di buat ini juga dapat di akses di berbagai tempat dan juga bisa diakses lewat smartphon sehingga mempermudah pengguna khususnya siswa/siswi yang berada di pelosok desa yang nantinya akan mengikuti UNBK.

\subsection{Saran}

Pembuatan Simulasi UNBK ini masih jauh dari sempurna dan masih memiliki kekurangan seperti dibutuhkan jaringan internet untuk mengakses sistem dan tampilan desain antarmuka yang lebih baik agar pengguna tertarik menggunakan Simulasi UNBK ini. Oleh karena itu, masih diperlukan pengembangan pada penelitian selanjutnya agar mampu lebih mengembangkan simulasi UNBK ke tingat yang lebih tinggi lagi, agar lebi bermanfaat untuk pengguna atau siswa/siswi nantinya.

Demikian saran yang diberikan, semoga saran tersebut dapat menjadi masukan bagi pihak pengelola dan dapat bermanfaat bagi penulis serta pengguna.

\section{DAFTAR PUSTAKA}

[1] Asikin H., 2018, Manajemen Kinerja Kepala Sekolah dan Guru Dalam Peningktan Mutu Pendidikan Anak Usia Dini, Kupang (ID): PROSIDING SEMAU 2016

[2] Hidayat R., 2010, Cara Praktis 
Membangun Website Gratis,

Jakarta(ID): PT Elex Media

Komputindo Kompas-Gramedia

[3] Kristanto Andri, 2003, Perancangan

Sistem Informasi dan Aplikasinya,

Penerbit Gava Media, Yogyakarta

[4] Pakpahan R., 2016, Model Ujian

Nasional Berbasis Komputer Manfaat Dan Tantangan, Jakarta (ID).

[5] Pressman, R.S. (2010). Software Engineering A Practitioner's Approach 7th Edition. McGraw-Hill Higher Education.

[6] Rusmawan U., 2017, Membangun Model Aplikasi Ujian Nasional Berbasis Komputer (UNBK), Vol.4, Bekasi Timur (ID).

[7] Siregar K. 2016, Simulasi dan Pemodelan Aplikasi Untuk Keteknikan Pertanian, Yogyakarta (ID): Deepublish 